\title{
РЕАЛИЗАЦИЯ ПРИЕМОВ МНЕМОТЕХНИКИ ПРИ ОБУЧЕНИИ УСТНОМУ ПОСЛЕДОВАТЕЛЬНОМУ ПЕРЕВОДУ
}

\section{IMPLEMENTATION OF MNEMONICS TECHNIQUES IN TEACHING CONSECUTIVE INTRPRETATION}

\section{Kopreva \\ N. Naumenko}

Summary: The relevance of mnemonics techniques research is of significant interest due to the fact that nowadays the use of mnemonics is gaining more and more popularity in the educational process and contributes to the development of students' memory. Memory processes and psychology are widely analyzed by the scientific community, opening up new possibilities of mnemonic techniques employment and their application into educational practice. The purpose of this article is to study the types and techniques of mnemonics, practical basis, as well as to prove the effectiveness of their implementation in teaching consecutive interpretation. To achieve the objective, the following tasks were set: 1) to give a definition to the concept of "mnemonics"; 2) to study the types and techniques of mnemonics; 3 ) to analyze their use in the practice of foreign language teaching. The authors focus on the analysis and specifics of working with the techniques of mnemonics, as well as difficulties in a number of tasks while teaching cadets at a military school. A selection of exercises from a number of school books was an example of teaching the techniques of mnemonics.

Keywords: concept of "mnemonics", components of mnemonics, types of mnemonics, techniques of mnemonics, types of memory.
Копрева Лариса Геннадиевна

К.филол.н., дочент, Краснодарское высшее военное авиачионное училище летчиков

successalways42@mail.ru

Науменко Наталия Павловна

старший преподаватель, Краснодарское высшее военное авиационное училище летчиков ladoshan88@mail.ru

Аннотация: Актуальность исследования приемов мнемотехники представляет существенный интерес в связи с тем, что в настоящее время применение мнемотехники в учебном процессе приобретает значительную популярность и влияет на развитие памяти обучающихся. Процессы памяти и психология широко анализируются научным сообществом, открывая новые возможности использования приемов мнемотехники и их внедрение в образовательную практику. Целью данной статьи является изучение видов и приемов мнемотехники, практическое обоснование, а также доказательство эффективности их реализации при обучении устному последовательному переводу. Для достижения цели были поставлены следующие задачи: 1) дать определение понятию «мнемотехника»; 2) рассмотреть виды и приемы мнемотехники; 3) проанализировать их использование в процессе преподавания иностранного языка. Особое внимание авторы акцентируют на анализе и специфике работы с приемами мнемотехники, а также трудностях при выполнении ряда заданий при обучении курсантов в военном вузе. Примером обучения приемам мнемотехники послужила выборка упражнений из ряда учебных пособий.

Ключевые слова: понятие «мнемотехника», составляющие мнемотехники, типы мнемотехники, приемы мнемотехники, виды памяти.

В науке конца XIX - начала XX вв. ряд психологов и педагогов, таких как С.Д. Файнштейн, Г.И. Челпанов, Х.М. Шиллер-Школьник также уделяли должное внимание вопросам механизмов запоминания. Значительный вклад в формирование определенных техник, способствующих облегчению процесса усвоения информации, внесли М.А. Зиганов, С.С. Матвеев, А.К. Колеченко, И.Ф. Матюгин, Т.Б. Полянская, Е.Д. Сафронова, С.Л. Рубинштейн и др.

Рассмотрим дефиниции термина. Большой психологический словарь предлагает такое определение: «мнемотехника» - (от греч. mnemonikon - искусство запоминания) - «совокупность специальных приёмов и способов, облегчающих запоминание нужной информации и увеличивающих объём памяти путём образования ассоциаций (связей)» [12, с. 47].

По утверждению В.А. Козаренко, мнемотехникой является «система внутреннего письма, созданная на 
основе непосредственной записи в мозг связей между зрительными образами, обозначающими ключевые элементы запоминаемой информации» [7, с. 29]. Как указывает психолог А.А. Леонтьев, «мнемотехника - это установление связей между запоминаемыми и хорошо знакомыми объектами» [9, с. 56].

Основатель и научный руководитель Ломоносовской школы М.А. Зиганов разделяет всю запоминаемую информацию в мнемотехнике на три группы:

1. образную (воспринимаемые человеком зрительные образы);

2. речевую (воспринимаемая устная речь и читаемые тексты);

3. точную (сведения, которые не имеют смысла запоминать приблизительно, должны запоминаться со 100 \%-ной точностью: телефонные номера, даты исторических событий, адреса, термины и понятия, шифры и коды, фамилии и имена, другие аналогичные сведения) [6, с. 19].

Специалист в области мнемотехники С.С. Матвеев выдвигает три основные составляющие мнемотехники:

1. ассоциация (связи между предметами, благодаря которым представление одного предполагает появление другого);

2. размещение (упорядочивание запоминаемых элементов);

3. воображение [11, с. 87].

При обучении устному последовательному переводу исследователь С.В. Визгина выделяет шесть типов мнемотехник, используемых на практике:

1. «актуализация когнитивного контекста», т.е. навык актуализации концептов как «пучка» представлений, понятий, знаний, ассоциаций, переживаний, которые сопровождают слово, позволяющий получать доступ к недостающей информации;

2. «выявление прагматики коммуникативного акта», т.е. сознательный подход к пониманию интересов и целей говорящего, осуществляющийся через механизмы проекции и интроекции в рамках эмпатического анализа как компонента переводческого осмысления текста;

3. «поиск смысловых ассоциаций с целью увеличения объема оперативной памяти», т.е. связывание собственных мыслей с содержанием сообщения с целью углубления процесса понимания;

4. «визуализация или конструирование мнемообразов»;

5. «установление ассоциативных связей между элементами информации на уровне языка»;

6. «редуктивное структурирование», т.е. сведение услышанной информации к неким ядерным элементам, которые помогают мысленно упорядочить содержание входящего сообщения [4].
Одним из профессионально значимых факторов, влияющих на эффективность деятельности устного переводчика, является хорошая память. При этом память определяется как «совокупность информации, приобретенной мозгом и управляющей поведением» [5, с. 76] или как «общефункциональный механизм, связанный с сохранением и использованием в последующей деятельности информации, полученной от взаимодействия с окружающим миром» [13, с. 135].

Если рассмотреть разные виды памяти и представить некоторые особенности описания мнемических процессов, происходящих при обучении устному последовательному переводу, анализ показывает, что существует ряд классификаций типов памяти применительно тому, какой аспект памяти взять за основу. Известный психолог С.Л. Рубинштейн указывает, что «в зависимости от характера деятельности, в ходе которой совершается запоминание, различаются непроизвольное и произвольное запоминание» [14, с. 85]. Безусловно, процесс запоминания представляется произвольным в устном последовательном переводе. При этом специалист в данной области осознанно сосредоточивается на восприятии, анализе и запоминании. Немаловажным для характеристики устного последовательного перевода считается способ запоминания, и «в этом плане различаются механическое и смысловое запоминание» [14, с. 87]. Следует сказать, что механическое запоминание непродуктивно, поскольку устный последовательный перевод возможен благодаря именно усвоению запоминания, обеспечивающему целостность и корректность перевода.

Добавим, что в большей степени активирована именно кратковременная память, выполняющая важную роль на каждом этапе переводческого процесса. В.Н. Андреева считает, что кратковременную память необходимо тренировать на удержание небольшого объема информации, релевантной конкретной ситуации, которая включает сведения о лицах, принимающих участие в ситуации профессионального взаимодействия, понимание цели коммуникации, тематические знания [2, с. 16-17].

Мнемотехника находит применение в основном в области обучения определенному виду перевода, в котором устный переводчик, облекая усвоенную и сохраненную информацию в такие формы языка, как фонетические, синтаксические, лексические и морфологические, осуществляет перевод. Подчеркнем, что сам процесс происходит именно в кратковременной памяти, поскольку специалист, имеющий дело с устным последовательным переводом, упорядочивает, а затем представляет результат в качестве значимой информации.

Известно, что существует ряд приемов и способов для запоминания информации. Так, В.Д. Шадриков и 
Л.В. Черемушкина предлагают следующие из них: группировка, выделение опорных пунктов, классификация, структурирование, систематизация, схематизация, аналогия, перекодирование, ассоциация, повторение и др. $[15$, c. 78$]$.

Некоторые зарубежные специалисты подходят к мнемотехническим методам и приёмам по-разному. Например, А.Д. Баддели классифицирует их как зрительные и словесные образы [16, с. 125].

Британский ученый И. Томпсон в своей работе "Memory in Language Learning" выделяет пять категорий исследуемых приёмов: лингвистические, пространственные, зрительные, вербальные и методы физической реакции (отклика) [17, с. 56].

В настоящее время преподаватели разрабатывают и внедряют свои собственные методики, опираясь на полученный практический опыт в учебных заведениях. М.Р. Ванягина полагает, что «в последние годы все большую значимость приобретают технологии активного обучения, формирующиеся на творческом, продуктивном мышлении и коммуникации. Их появление связано со стремлением преподавателей активизировать познавательную деятельность студентов, побуждать их к самостоятельному получению знаний, создавать оптимальные условия для овладения профессионально значимыми компетенциями, практическими умениями и навыками» [3].

Приемы запоминания, сформированные в разных системах и школах памяти мира, были упорядочены, усовершенствованы и сгруппированы в одну целостную систему, с целью удовлетворить трём основным принципам: простоте, универсальности и эффективности.

В.А. Козаренко выделяет 3 этапа запоминания:

1. кодирование: преобразование слова в образы;

2. запоминание: образование связи между опорными образами и запоминаемыми образами;

3. закрепление связей в мозге: исключение промежуточных образов из головы посредством образования прямой связи слово (произношение)образ-значение слова [7, с. 45].

Данная классификация используется преподавателями военного авиационного вуза при подготовке переводчиков в сфере профессиональной деятельности.

При описании первого этапа автор предлагает следующие приемы:

а) Слово-образ, как известно, уникальным источником смыслонаполнения понятий, хранящихся в сознании, являются те визуальные образы, с которыми современный человек сталкивается в своей жизни, на работе, учебе или досуге [8, с. 68]. Здесь присущи простые образы, возникающие в процессе припоминания лексических единиц. Например, обучающимся были предложены наглядные изображения по авиационной тематике - типы самолетов: истребитель, бомбардировщик, штурмовик и учебно-тренировочный самолет.

На основе представленных визуальных средств возникает образ действия. Так, глагол "to fight" (сражаться) подсказывает название типа самолета, выполняющего данное действие: «сражающийся» - "fighter" - истребитель. Последующие предлагаемые изображения ЛА (летательный аппарат) аналогичным образом помогают догадаться о названии самолета:

$$
\begin{aligned}
& \text { to bomb-bomber } \\
& \text { to attack - an attack plane } \\
& \text { to train - trainer }
\end{aligned}
$$

Таким образом, данный прием позволяет активизировать функции памяти и внимания, а также сформировать единое системное представление об изучаемой лексике.

б) Прием символизация. Характеризуется как более сложный, поскольку происходит преобразование абстрактных слов в зрительные образы. Например, в следующих терминах take off - взлет, отрыв возникает образ взлетающего ЛА, что символизирует первый этап полета. При этом послелог "оff" помогает догадаться об отрыве «от земли».

Рассматривая термин "flight level" (FL), обучающиеся опираются на слово "level", знакомое им как "уровень». Однако уже известное значение слова "flight" позволяет им на основе зрительного образа применить употребляемый авиационный термин «эщелон полета».

Используя подобный прием, обучающимся было предложено определить значение термина "landing" без зрительный опоры, исходя из известного им слова "land". Визуальное же изображение помогает догадаться о переводе происходящего действия "landing" - приземление, посадка (прочесс). Как показывает практика, особого труда не составило понять значение и перевод ing формы.

в) Образные коды рассматриваются как фонетические, поскольку для определённого звука формируется свой образ и уже к образу-значению добавляется фонетический. Например, обучающимся знакомо слово "altimeter" - «высотомер», а окончание "meter" наводит их на мысль о том, что данный прибор измеряет высоту.

Следующий этап осуществляется посредством соединения образов. В воображении курсантов могут быть 
соединены несколько зрительных образов, и происходит запоминание взаимосвязи между ними. Например, в дополнении к терминам, означающих этапы полета (take-off, flight level, landing) прилагаются промежуточные действия, происходящие между ними, а именно climbing (от "to climb"- набирать высоту) и descending (от "to descend"- снижаться), отмечая, что существительное имеет иную форму descent - спуск, снижение.

Добавим, что фотофрагменты могут быть дополнены видеосюжетами, иллюстрирующими действие в процесce.

Третий этап предполагает многократное запоминание информации и представляет собой следующую схеmy:

а) запомнить информацию (создать связи);

б) воспроизвести всю информацию в голове (контрольное припоминание);

в) сверить с источником (если без ошибок, повторное припоминание осуществить через час);

г) припоминать информацию через 3-4 дня по три раза в день [7, с. 46].

На основе предъявленных способов запоминания рассмотрим существующие мнемотехнические упражнения при обучении устному последовательному переводу. Л.К. Латышевым и В.И. Провоторовым предлагаются три вида упражнений:

1. зачитывается фрагмент текста на русском или иностранном языке; задача обучающихся заключается в точном воспроизведении данных отрывков;

2. зачитываются отрывки, содержащие прецизионную лексику (географические названия, имена собственные, даты и т.д.); перед обучающимися стоит аналогичная задача, что и при выполнении предыдущего упражнения;

3. зачитывается ряд слов на русском, иностранном языке (или на обоих языках); обучающиеся должны воспроизвести последовательность, по возможности не меняя порядка следования слов [10, c. 113-114].

Другие типы упражнений выделяются И.С. Алексеевой, а именно: слова, ряды чисел, топонимы, имена, реалии-деньги и реалии-меры, мнемостихи, «снежный ком», запоминание текста, внимание переводчика, мнемотехника и логические операции, смешанный тренинг по мнемотехнике [1, с. 45].

Представим специфику работы, проводя краткий обзор приемов мнемотехники при обучении курсантов устному последовательному переводу. Нижеприведенные задания иллюстрируют формирование навыка запоминания.
1. На начальном этапе обучающимся зачитываются ряд слов, первоначально 3-4 (например: истребитель, бомбардировщик, штурмовик), они должны их повторить. Стоит подчеркнуть, что тематическое единство лексического ряда в данном случае предпочтительно, поскольку устный перевод, как правило, включает семантически близкие компоненты.

2. Следующий этап по сложности включает повторение 4-6 слов на иностранном языке и перевод их на русский: flight, group, squadron; tons, inches, gallons. Отметим, что тематический принцип удобно применять в подготовительных упражнениях перед освоением конкретной текстовой информации при работе над переводческими жанрами.

Работа с прецизионной лексикой представляет особый этап при обучении приемов мнемотехники. Поскольку переводчику часто приходится запоминать так называемые блоки прецизионной информации - числа, даты, имена, названия, которые не восстанавливаются из контекста и требуют точной передачи, для этого преодолению навыков логически организованного и ассоциативного запоминания, а также тренировке навыков линейного (без опоры на логику) и безассоциативного запоминания, уделяется должное внимание. Добавим, что при выполнении успешного двустороннего перевода - переход с одного языка на другой, специалисту, безусловно, необходимо владеть определённым навыком как при восприятии, так и в продуцировании речи. Все нижеприведенные задания предлагаются без зрительной опоры. Для овладения приемами мнемотехники обучающимся были предложены ряд последовательных чисел с целью повторения их в том же порядке: сначала на родном языке, затем на иностранном. Например:

23884168,97788 13, 41635772,447780 29, 833768 $53,77173782,68333446$.

Практика показала, что при выполнении задания подобного рода возникают определенные трудности, такие как неспособность воспроизвести числа, соблюдая порядок следования.

Подобная ситуация наблюдалась и при работе с другими видами заданий. Например, повторить каждым обучающимся по одному предложению построчно. При этом следующее должно воспроизводиться очередным курсантом. Целью является произнесение отдельного предложения дважды. При этом возникли трудности: соблюдение заданного темпа и предложенного порядка слов.

1. The first was a private in a soldier's blouse. The second was a well-trained sergeant in tarpaulin boots.

The third was a tall warrant officer in his thirties. The fourth was a dress uniformed lieutenant. 
The fifth was a skilled captain worn in a field uniform should-belt.

The sixth was a strict major dressed in a jacket with one star.

The seventh was a bald lieutenant colonel with a briefcase.

The eighth was a colonel in a grey fir papakha.

The ninth was a major-general in trousers stripes.

The tenth was a determined lieutenant general in a jacket with two stars.

The eleventh was serviceman of the highest rank with Marshal's baton shown power of the Army.

2. A pilot flies an aircraft.

A captain commands the crew of an aircraft.

A co-pilot assists a commander to fly an aircraft. A navigator determines the route of an aircraft. A flight engineer controls the systems of an aircraft. A gunner operates the armament of an aircraft.

Однако подчеркнем, что при выполнении представленных заданий, обучающиеся все-таки стремятся осуществить поставленную задачу, демонстрируя интерес к подобным типам упражнений.

При работе с профессионально-ориентированной лексикой наблюдались определённые трудности при запоминании значительного количества лексических единиц. Поскольку мнемостихи воспринимаются намного легче благодаря фонетическим созвучиям рифмованных окончаний слов, для облегчения их закрепления предлагался следующий мнемостих:

This is an altitude that is measured by an altimeter.

The speed that indicated by a speedometer.

The heading is shown by a heading indicator.

The vertical speed is displayed by vertical speed indica- tor.

Следующим наиболее эффективным и довольно распространённым приёмом мнемотехники среди педагогов и лингвистов является метод ассоциаций, нацеленный на запоминание иноязычных слов. Данный метод предполагает выбор русского слова (словосочетания) созвучного иностранному. При этом обучающиеся, припоминая его на родном языке, автоматически воспроизводят ассоциативную связь со значением заданной лексической единицы. Конечным результатом считается четкий запоминающийся образ. Важно, чтобы ассоциации были нестандартными, однозначными, возможно забавными, способствующими более быстрому усвоению. Например, термин "ejection seat" легко вывести через фонетическую ассоциацию: "seat" - «сидеть, сиденье», противопоставляя значения "injection"- «инъекция, вводить» и обратное ему "ejection" без затруднений определяется название системы в кабине пилота - «выбрасываемое кресло», т.е. «катапультное кресло».

Итогом подобного представления материала стало более продуктивное запоминание новых лексических единиц. Каждый из рассматриваемых этапов демонстрирует определённый навык, требующий тренировки, памяти, внимания, закладывающий основу для формирования важного переводческого навыка.

Резюмировав вышесказанное, можно сделать вывод о том, что реализация приемов мнемотехники при обучении устному последовательному переводу способствует быстрому и эффективному запоминанию материала, развивая коммуникативную и познавательную деятельность, при этом повышая мотивацию обучающихся и делая сам процесс результативным и увлекательным.

\section{ЛИТЕРАТУРА}

1. Алексеева И.С. Профессиональный тренинг переводчика: Учебное пособие по устному и письменному переводу для переводчиков и преподавателей. СПб.: Союз, 2001. - 145 c.

2. Андреева В.Н. Психолингвистичекие модели функционирования памяти при синхронном переводе // Вестник Российского государственного университета им. И. Канта. - 2007. - № 2. - С. 16-21.

3. Ванягина М.Р. Применение мнемотехники при обучении иноязычной лексике. [Электронный ресурс]. URL https://cyberleninka.ru/article/n/primeneniemnemotehniki-dlya-obucheniya-inoyazychnoy-leksike/viewer. (дата обращения: 25.09.2021).

4. Визгина С.В. Мнемотехники в обучении устному переводу. МГЛу. Минск. [Электронный ресурс]. URL: http://spr.fld.mrsu.ru/2020/05/mnemotekhniki-vobuchenii-ustnomu-perevodu/. (дата обращения: 07.09.2021).

5. Годфруа Ж. Что такое психология: В 2-х т. Изд. 2-е, стереотипное. - Т. 1 / Пер. с франц. - М.: Мир, 1996. - 348 с.

6. Зиганов М.А. Мнемотехника. Запоминание на основе визуального мышления. - М: Школа рационального чтения, 2000. - 200с.

7. Козаренко В.А. Учебник мнемотехники. Система запоминания «Джордано». - М., 2007. - 115с.

8. Казаченко 0.В. Патриотизм как имидж (психолингвистический аспект) / О.В. Казаченко, Л.А. Хамула // Вестник Марийского государственного университета. - 2019. - Т.13. - №1 (23). - С. 68-75.

9. Леонтьев А.А. Психологические предпосылки раннего овладения иностранными языками // ИЯШ. - 1985. - №5. - С.24-30.

10. Латышев Л.К., Провоторов В.И. Структура и содержание подготовки переводчиков в языковом вузе: Учебно-методическое пособие. - 2-е изд., стереотип. - М.: НВИ-ТЕЗАУРУС, 2001. - 136с. 
11. Матвеев С.С. Феноменальная память: Методы запоминания информации [Текст] / С. С. Матвеев. - М.: Альпина П., 2013. - 225 с.

12. Мещеряков Б.Г., Зинченко В.П. Большой психологический словарь. - М.: Олма-пресс, 2004. - 632с.

13. Нелюбин Л.Л. Толковый переводоведческий словарь: 3-е изд., перераб. - М.: Флинта, Наука, 2003. - 320с.

14. Рубинштейн С.Л. Основы общей психологии: В 2 т. Т.1. - М.: Педагогика, 1989. - 326 с.

15. Шадриков Владимир Дмитриевич. Мнемические способности: развитие и диагностика / В.Д. Шадриков, Л.В. Черемошкина. - М. : Педагогика, 1990. $175 \mathrm{c}$.

16. Baddeley A.D. Essentials of Human Memory. - Hove, East Sussex: Psychology Press, 1999. - 368 p.

17. Thompson I. Memory in Language Learning // Learner Strategies in Language Learning / ed. by A. Wenden, J. Rubin. 1987. - 321 p.

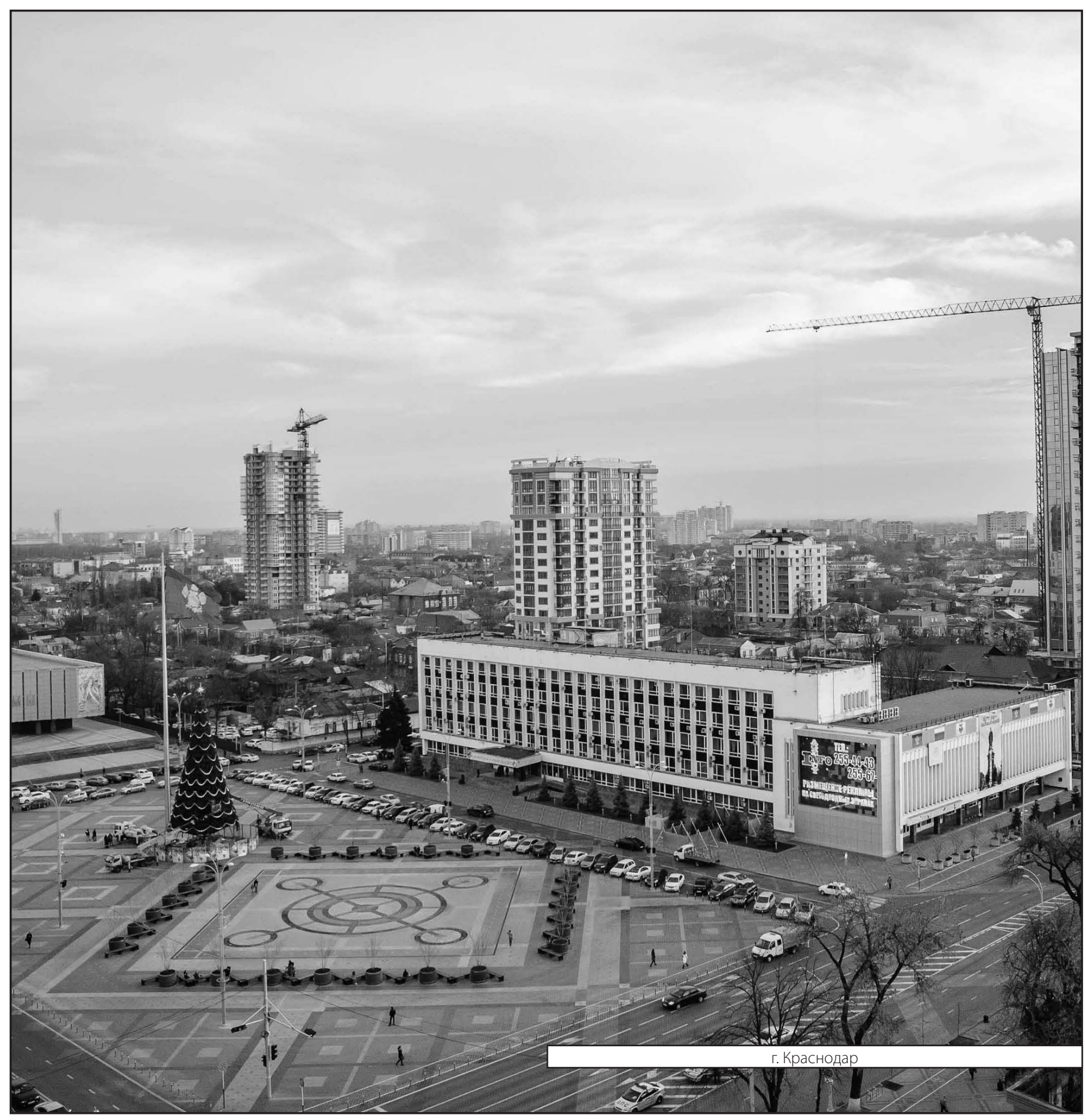

